\title{
FORMULASI DAN EFEKTIFITAS SAMPO EKSTRAK BUAH PEDADA (Sonneratia caseolaris L) SEBAGAI ANTIKETOMBE TERHADAP Candida albicans
}

\author{
Dwi Kurniawati Sambodo ${ }^{1}$, Lisa Erie Yani $^{2}$ \\ ${ }^{1,2}$ STIKES Surya Global Yogyakarta \\ Email Korespondensi : antareszaman@gmail.com
}

\begin{abstract}
ABSTRAK
Ketombe merupakan salah satu masalah di kulit kepala dengan gejala umum adanya sisik-sisik (pengelupasan kulit mati), gatal pada kulit kepala dan kemerahan di sekitar kulit kepala. Ketombe dapat disebabkan oleh kulit kepala yang berminyak, hormon atau jamur. Salah satu jamur penyebab ketombe adalah Candida albicans. Berdasarkan penelitian yang telah dilakukan terdapat alkaloid pada ekstrak etanol buah pedada. Secara umum, alkaloid dapat digunakan sebagai antijamur. Berdasarkan hal tersebut ekstrak metanol buah pedada dapat dijadikan bahan utama dalam pembuatan sampo antiketombe. Penelitian ini bertujuan untuk memformulasikan dan menguji efektifitas sampo ekstrak buah pedada sebagai antiketombe terhadap Candida albicans. Buah pedada diekstraksi menggunakan metode maserasi bertingkat dengan pelarut metanol. Sampo ekstrak buah pedada diformulasikan dengan variasi konsentrasi ekstrak menjadi 3 formula. Sampo diuji sifat fisik dan efektifitas antiketombe menggunakan metode Diffusion Kirby-Bauer dengan Media PDA. Dari hasil yang diperoleh dapat disimpulkan bahwa sifat fisik dari ketiga formula sampo ekstrak buah pedada (Sonnerratia caseolaris $\mathrm{L}$ ) meliputi organoleptis, pengukuran $\mathrm{pH}$, pengukuran tinggi busa, cycling test, dan viskositas dihasilkan sifat fisik yang baik sesuai dengan standar uji sifat fisik sampo, namun hasil uji homogenitas menunjukan sampo formula III kurang homogen. Ketiga formula sampo efektif sebagai antiketombe terhadap jamur Candida albicans.
\end{abstract}

Kata Kunci : Sampo Antiketombe, Buah Pedada, Candida albicans. 


\title{
FORMULATION AND EFFECTIVENESS OF PEDADA (Sonneratia caseolaris L) EXTRACT SHAMPOO AS AN ANTIDANDRUFF AGAINST Candida albicans
}

\begin{abstract}
Dandruff is one of the problems on the scalp with common symptoms of scales (exfoliation of dead skin), itching of the scalp and redness around the scalp. Dandruff can be caused by an oily scalp, hormones or fungus. One of the fungi that cause dandruff is Candida albicans. Based on research that has been done there are alkaloids in the ethanol extract of pedada fruit. In general, alkaloids can be used as an antifungal. Based on this, the methanol extract of pedada fruit can be used as the main ingredient in the manufacture of anti-dandruff shampoo. This study aims to formulate and test the effectiveness of the pedada fruit extract shampoo as an anti-dandruff against Candida albicans. Pedada fruit was extracted using multilevel maceration method with methanol as a solvent. Pedada fruit extract shampoo is formulated with variations in extract concentration into 3 formulas. Shampoo was tested for physical properties and effectiveness of anti-dandruff using the Kirby-Bauer Diffusion method with PDA media. From the results obtained it can be concluded that the physical properties of the three formulas of pedada fruit extract shampoo (Sonnerratia caseolaris L) include organoleptic, pH measurement, foam height measurement, cycling test, and viscosity produced good physical properties in accordance with the standard test of the physical properties of shampoo, however Homogeneity test results show that formula III shampoo is less homogeneous. All three shampoo formulas are effective as anti-dandruff against the fungus Candida albicans.
\end{abstract}

Keywords : Anti-dandruff shampoo, Pedada Fruit, Candida albicans.

\section{PENDAHULUAN}

Rambut merupakan bagian dari tubuh yang berfungsi untuk meningkatkan penampilan secara visual baik untuk pria maupun wanita. Karena itu, rambut harus selalu dijaga kebersihan dan kesehatannya. Seperti bagian tubuh yang lain, rambut juga memiliki masalahnya sendiri. Salah satu masalah rambut yang dapat mengganggu penampilan dan keindahan rambut adalah ketombe. Ketombe merupakan salah satu masalah di kulit kepala dengan gejala umum adanya sisiksisik (pengelupasan kulit mati), gatal pada kulit kepala dan kemerahan di sekitar kulit kepala. Ketombe dapat disebabkan oleh kulit kepala yang berminyak, hormon atau jamur. Salah satu jamur penyebab ketombe adalah Candida albican (Ambarwati, dkk., 2016).

Sediaan sampo antiketombe merupakan sediaan yang sering dipakai sehari-hari dan dapat digunakan untuk menanggulangi dan menghindarkan kulit kepala dari ketombe yang berlebihan, dimana sampo ini mengandung zat aktif antijamur yang efektif sebagai antiketombe. Saat ini masyarakat 
cenderung lebih menyukai obat dan kosmetik yang berasal dari alam.

Diketahui secara empiris buah masak pedada (Sonneratia caseolaris L.) dapat mengatasi masalah ketombe. Di kampung Batu-Batu, Kecamatan Gunung Tabur, Berau, Kalimantan Timur, buah pedada banyak ditemukan, namun pengolahannya sebatas dibuat produk berupa sirup, selai dan dodol. Sejauh ini belum begitu banyak upaya masyarakat untuk mengatasi masalah ketombe dengan menggunakan buah tersebut (Lisa, E. Wawancara dengan warga desa batu-batu. 21 oktober 2018). Berdasarkan penelitian yang telah dilakukan sebelumnya, didapatkan senyawa metabolit sekunder ekstrak metanol kulit buah pedada yang merupakan senyawa murni berwarna putih berbentuk serbuk yang diidentifikasi sebagai senyawa golongan alkaloid. Secara umum, alkaloid dapat digunakan sebagai antijamur (Mutiara, dkk., , 2016).Berdasarkan hal tersebut ekstrak metanol buah pedada dapat dijadikan bahan utama dalam pembuatan sampo antiketombe. Penelitian ini bertujuan untuk memformulasikan dan menguji efektifitas sampo ekstrak buah pedada sebagai antiketombe terhadap Candida albicans.

\section{METODE PENELITIAN}

\section{Material}

Alat timbangan analitik, erlenmeyer (Pyrex), cawan petri (Pyrex), catton buds, mikro pipet (Ecopipette), beaker glass (Pyrex), autoclave, lampu spiritus, tabung reaksi (Pyrex), rak tabung reaksi, jarum ose, kertas saring, corong pisah (Pyrex), alumunium foil, penggaris berskala, pencadang, blender, rotary evaporator (Ika), viskometer Brokfield, gelas ukur, oven. Bahan
Buah pedada, metanol, natrium lauryl sulfas, cocomide DEA, cmc, metil paraben, akuades, PDA, suspensi Candida albicans, sampo ketomed®

\section{Preparasi Sempel}

Buah pedada diambil, dibersihkan, dirajang, dikeringkan, dibersihkan dari bahan yang tidak dipakai, dibuat serbuk, lalu ditimbang untuk mengetahui berat yang dihasilkan

\section{Ekstraksi}

Sebanyak 600 g serbuk simplisia Sonneratia caseolaris L dimasukkan ke dalam Bejana, kemudian direndam dengan larutan metanol sebanyak $3000 \mathrm{ml}$, ditutup dengan aluminium foil dan dibiarkan selama 5 hari sambil sesekali diaduk. Setelah 5 hari, sampel yang direndam tersebut disaring menggunakan kertas saring yng menghasilkan filtrat 1 dan ampas 1. Ampas yang ada kemudian ditambah dengan larutan metanol sebanyak $1500 \mathrm{ml}$ ditutup dengan aluminium foil dan dibiarkan selama 2 hari, sampel tersebut disaring menghasilkan filtrat 2 dan ampas 2. Filtrat 1 dan 2 dicampur menjadi satu lalu dievaporasi menggunakan rotary evaporator. Ekstrak kental yang dihasilkan dibiarkan pada suhu ruangan hingga seluruh pelarut metanol menguap . Ekstrak yang sudah didapat, ditimbang dan dihitung rendemennya.

$\%$ rendemen $=\frac{\text { berat ekstrak }}{\text { berat sampel }} \times 100 \%$

\section{Formulasi sampo}

Sampo diformulasikan menjadi FI, FII, FIII dengan perbedaan variasi ekstrak buah pedada berturut turut $2,5 \mathrm{~g} ; 5 \mathrm{~g} ; 7,5 \mathrm{~g}$ dalam $60 \mathrm{ml}$ sampo

\section{Uji efektifitas antiketombe}

a. Sterilisasi alat dan media 
Alat tahan panas, bahan dan media yang akan digunakan untuk penelitian disterilisasi menggunakan autoklaf selama 15 menit pada suhu $121^{\circ} \mathrm{C}$. Sebelumnya, alat-alat dicuci bersih, dikeringkan dan dibungkus dengan koran. Alat yang tidak tahan panas disterilkan dengan menggunakan alkohol. Alat-alat yang disterilkan menggunakan autoklaf meliputi erlenmeyer, batang pengaduk, cawan petri, jarum ose, media agar, kaca arloji.

b. Pembuatan Media Potato Dextrose Agar (PDA)

Pembuatan media agar dilakukan dengan mencampur 20 g PDA (Potatos Dexstrose Agar) dengan $512 \mathrm{ml}$ akuades dalam erlenmeyer. Medium dipanaskan di atas hot plate sambil diaduk sampai mendidih agar tercampur dengan sempurna. Kemudian didiamkan dan disterilkan di dalam autoklaf selama 15 menit, pada suhu $121^{\circ} \mathrm{C}$ (Atlas, 2004)

c. Peremajaan jamur uji

Jamur Candida albicans biakan murni yang diperoleh dari Fakultas Farmasi Universitas Gadjah Mada diambil satu ose lalu ditanam pada media PDA. Kemudian media PDA yang telah ditanam biakan jamur, diinkubasi pada suhu $37^{\circ} \mathrm{C}$ selama $18-24$ jam hingga didapatkan koloni jamur Candida albicans

d. Pembuatan Inokulum Jamur Candida albicans

Pembuatan inokulum jamur Candida albicans dilakukan dengan cara mensuspensikan 1 ose jamur Candida albicans hasil tahap peremajaan ke dalam $25 \mathrm{ml}$ media PDA. Lalu diinkubasi pada suhu $37^{\circ} \mathrm{C}$ selama 24 jam

e. Pembuatan Standar Mc Farland Pembuatan larutan standar Mc Farland dengan cara dicampurkannya $9,5 \mathrm{ml}$ larutan $\mathrm{H}_{2} \mathrm{SO}_{4} 1 \%$ dengan $0,5 \mathrm{ml}$ larutan $\mathrm{BaCl}_{2} 1 \%$ sehingga volume menjadi 10 $\mathrm{ml}$, lalu dikocok sampai homogen. Larutan harus dikocok setiap akan digunakan, untuk membandingkan suspensi bakteri

f. Pembuatan suspensi jamur

Koloni jamur Candida albicans diambil satu ose kemudian dimasukkan ke dalam $5 \mathrm{ml} \mathrm{NaCl} 0,9 \%$ dalam tabung reaksi lalu dikocok hingga homogen.

g. Pembuatan kontrol

Kontrol positif dibuat dengan menggunakan sampo ketomed $\AA$ dengan konsentrasi $2 \%$, dibuat dengan mencampurkan 0,02 g sampo ketomed dilarutkan dalam $1 \mathrm{ml}$ akuades.

Kontrol negatif menggunakan akuades sebanyak $1 \mathrm{ml}$.

h. Pembuatan larutan uji

Larutan uji dibuat dengan konsentrasi $15 \%$, 30\%, dan $60 \%$ dari setiap formula, dengan melarutkan $0,015 \mathrm{~g}$, $0,030 \mathrm{~g}$, dan $0,060 \mathrm{~g}$ setiap formula dalam $1 \mathrm{ml}$ akuades.

i. Pembuatan Media Uji

Pengujian aktivitas sampo terhadap pertumbuhan jamur Candida albicans dilakukan dengan teknik pour plate. Sebanyak $100 \mu \mathrm{L}$ suspensi jamur diteteskan pada media Potato Dextrose Agar (PDA), dan dioleskan secara merata menggunakan batang $\mathrm{L}$ steril pada media. Kemudian media diinkubasi lagi selama $1 \times 24$ jam. Setelah diinkubasi, taruh kertas cakram diatas media sebanyak 5 buah dan atur 
jarak sedemikian rupa sama antar kiri dan kanannya. Teteskan masingmasing kontrol dan ekstrak di atas kertas cakram. Sebagai kontrol positif digunakan sampo ketomed 2\% dengan konsentrasi $0,02 \%$ dan kontrol negatif digunakan larutan akuades, selanjutnya diinkubasi pada suhu $37^{\circ} \mathrm{C}$ selama 18 24 jam

j. Uji Daya Hambat

Uji daya hambat dilihat dari zona bening yang tersebar disekitar kertas cakram, pengukuran daya hambat menggunakan jangka sorong.

\section{Uji fisik Sampo}

a. Uji Organoleptis

Uji organoleptis ini dilakukan dengan cara 2 gram sampo diletakkan pada gelas beaker dengan melihat wujud, warna, aroma, dan rasa.

b. Uji viskositas

Uji viskositas ini dilakukan dengan cara sebanyak 100 gram sampo dimasukkan dalam beaker gelas $100 \mathrm{ml}$ kemudian diukur kekentalannya menggunakan viskometer Brookfield.

c. Uji Pengukuran $\mathrm{pH}$

Pengukuran $\mathrm{pH}$ dilakukan dengan cara 2 gram sampo dilarutkan dengan air lalu dilakukan pengukuran $\mathrm{pH}$ dengan menggunakan $\mathrm{pH}$ meter.

d. Uji Pengukuran Tinggi Busa

Uji stabilitas busa dilakukan dengan cara memasukkan sampo sebanyak 1 $\mathrm{ml}$ ke dalam gelas ukur $250 \mathrm{ml}$ ditambahkan air secara perlahan hingga mencukupi 100 ml. Dilakukan pengocokan ke kanan dan kiri selama 10 kali. Jalankan stopwatch ketika pengocokan dihentikan. Lalu diukur volume busa dalam gelas ukur dalam beberapa kurun waktu

e. Uji Daya Sebar

Uji daya sebar dilakukan dengan meletakkan $2 \mathrm{~g}$ sediaan sampo dipusat antara lempeng cawan petri dimana lempeng bagian atas dibebani dengan anak timbang seberat $25 \mathrm{~g}$ diatasnya. Permukaan yang dihasilkan dengan meningkatkan beban merupakan karakteristik daya sebar.

f. Uji Homogenitas

Uji homogenitas dilakukan dengan cara sediaan sampo yang dihasilkan dioleskan pada kaca objek kemudian diamati bagian- bagian yang tidak tercampurkan dengan baik.

g. Uji cycling tes

Uji dilakukan dengan cara menyimpan sediaan dari masing-masing formula yang ditempatkan dalam wadah gelas transparan sediaan disimpan pada suhu $4 \pm 2^{\circ} \mathrm{C}$ selama 24 jam, kemudian dipindahkan kedalam oven yang bersuhu $40 \pm 2^{\circ} \mathrm{C}$ selama 24 jam. Perlakuan ini adalah 1 siklus. Pengujian dilakukan sebanyak 6 siklus atau 12 hari dan diamati ada atau tidaknya perubahan yang terjadi pada masing-masing sediaan. Kondisi sediaan dibandingkan selama percobaan dengan kondisi sediaan sebelumnya.

\section{Analisis Data}

Data uji efektivitas sampo berupa diameter zona hambat yang diukur menggunakan jamgka sorong, data yang diperoleh diuji normalitas, dan dianalisis one way ANOVA, dan data hasil uji fisik menggunakan pengamatan. 


\section{HASIL DAN PEMBAHASAN Preparasi sampel}

Buah pedada yang digunakan berasal dari desa Batu-batu, Berau, Kalimantan Timur. Buah kemudian dicuci bersih, dipisahkan bagian-bagian pengotor, dirajang tipis, lalu kemudian dianginanginkan sampai kering. Tujuan buah dirajang tipis agar proses pengeringan lebih cepat. Pengeringan hanya dianginanginkan bertujuan agar zat berkhasiat pada buah berupa alkaloid tidak rusak terkena paparan sinar matahari atau terkena panas berlebih. Setelah buah kering, dijadikan dalam bentuk serbuk dengan cara diblender. Penyerbukan dilakukan untuk memperluas kontak pelarut dengan sampel dan mempermudah penarikan zat aktif yang terkandung dalam buah pedada. (Sambodo \& Arlesia, 2019)

\section{Ekstraksi}

Serbuk buah pedada diekstraksi dengan metode maserasi menggunakan pelarut metanol. Metode maserasi dipilih karena merupakan metode ekstraksi yang sederhana dan dapat menyari senyawa yang tidak tahan terhadap pemanasan dan menghasilkan rendemen yang lebih tinggi dibandingkan dengan pelarut lain yang memiliki polaritas lebih rendah. Proses ini sangat menguntungkan dalam isolasi senyawa bahan alam, karena selama perendaman terjadi peristiwa plasmodisis yang menyebabkan terjadi pemecahan dinding sel akibat perbedaan tekanan di dalam dan di luar sel, sehingga senyawa yang ada dalam sitoplasma akan terlarut dalam pelarut organik dan proses ekstraksi senyawa akan sempurna karena dapat diatur lama perendaman yang diinginkan (Nurdiansyah, 2007).

Hasil ekstraksi kemudian dikentalkan dengan rotary evaporator pada suhu $40^{\circ} \mathrm{C}$ agar zat aktif pada sampel tidak rusak akibat pemanasan yang terlalu tinggi. Prosesnya dilakukan sampai diperoleh larutan pekat. Didapatkan randemen dari pengentalan ekstrak ini 17,52\%. Ekstrak buah pedada yang didapatkan diformulasikan menjadi sediaan sampo.Sampo ekstrak buah pedada diformulasi menjadi 3 formula dengan perbedaan terletak pada konsentrasi ekstrak yng digunakan, hal tersebut dimaksudkan untuk membandingkan sifat fisik dan efektifitas antiketombe pada masing-masing formula.

\section{Organoleptis}

Hasil uji organoleptis semua formula sampo ekstrak buah pedada berwarna coklat, berbau mint dan berbentuk kental. Warna ketiga formula sampo sesuai dengan ekstrak buah pedada yang digunakan, bau mint pada sampo didapat dari oleum mint yang digunakan sebagai pewangi pada ketiga formula sampo, dan bentuk kental pada sampo didapat dari CMC yang digunkan sebagai penstabil dan pengental dalam sediaan sampo.

\section{Viskositas}

Sampo ekstrak buah pedada (Sonneratia caseolaris L) FIII memiliki viskositas paling besar yakni 2892,33, diikuti FII 2589,33, dan F1I dengan viskositas paling kecil yakni 1860 . Viskositas formula sediaan sampo ekstrak buah pedada pada FI tidak memenuhi nilai viskositas yang ideal karena kurang dari 2000 sedangkan FII dan FIII telah mencapai nilai viskositas yang ideal yaitu lebih dari 2000 cps. Hal ini menunjukkan bahwa nilai uji viskositas sampo formula 2 dan 3 sesuai dengan standar viskositas yakni pada rentang 2000 - 3000 cps. Semakin besar konsentrasi ekstrak buah pedada yang digunakan maka semakin besar viskositas sampo pada masingmasing formula (Rieger, 2003) 


\section{Homogenitas}

Hasil homogenitas sampo formula 1 dan 2 homogen, menunjukan ekstrak buah pedada tersebar merata pada sediaan sampo, tetapi pada formula 3 didapat hasil kurang homogen ditunjukan dengan adanya bintik-bintik hitam ekstrak buah pedada pada sampo saat pengujian.

\section{Tinggi Busa}

Dari ketiga formulasi sampo dengan 3 variasi ekstrak menunjukkan pengukuran tinggi busa sesuai dengan standar pada umumnya dalam rentang tinggi 1,3-22 $\mathrm{cm}$ (Wilkinson \& Moore, 1982). hal ini menunjukan surfaktan pada sampo ekstrak buah pedada memiliki kemampuan membuasa, namun tinggi busa tidak mempengaruhi daya bersih sampo.

\section{Cycling test}

Hasil uji Cycling test yang diamati secara organoleptis menunjukkan bahwa tidak teradinya pemisahan antar fase pada ketiga formula. Hal ini menunjukkan bahwa sediaan sampo stabil pada penyimpanan suhu ekstrim dan variasi konsentrasi ekstrak buah pedada tidak mempengaruhi kestabilan krim pada penyimpanan saat perubahan suhu yang ekstrim.

pH

Hasil uji pH sampo ekstrak buah pedada formula 1, 2, dan 3 berturut-turut sebesar 5,9; 5,8 dan 5,8 hal ini menunjukan bahwa $\mathrm{pH}$ ketiga formula sampo memenuhi persyaratan $\mathrm{pH}$ sampo yaitu 5,0-8,0 (Badan Standardisasi Standar Nasional Indonesia, 1992). pH sampo ekstrak buah pedada juga berada dalam rentang 5,0-6,0 yakni $\mathrm{pH}$ kulit kepala sehingga $\mathrm{pH}$ sampo ekstrak buah pedada tidak mengiritasi kulit kepala.

\section{Efektifitas antiketombe}

Tabel 1. Hasil uji antijamur sampo antiketombe ekstrak buah pedada (Sonneratia caseolaris L.)

\begin{tabular}{lcccc}
\hline & \multicolumn{3}{c}{ Daya hambat $(\mathrm{mm})$} & Rata-rata $(\mathrm{mm})$ \\
\hline Replikasi & 1 & 2 & 3 & \\
\hline Kontrol + & 17,45 & 16,5 & 16,45 & 16,8 \\
\hline Kontrol - & 0 & 0 & 0 & 0 \\
\hline F1 15\% & 14,1 & 15,8 & 14,5 & 14,8 \\
\hline F1 30\% & 15,3 & 16,26 & 14,96 & 15,5 \\
\hline F1 60\% & 15,6 & 15,95 & 17,56 & 16,37 \\
\hline F2 15\% & 16,35 & 17,3 & 17,63 & 17,07 \\
\hline F2 30\% & 19,2 & 18,6 & 12,6 & 19,9 \\
\hline F2 60\% & 19,3 & 22,7 & 17,8 & 20,47 \\
\hline F3 15\% & 24,6 & 24 & 21,53 & 23,37 \\
\hline F3 30\% & 27,53 & 18,8 & 25,7 & 23,9 \\
\hline F3 60\% & 24,4 & 24,7 & 23,3 & 24,8 \\
\hline S Sumbr Dat Prim & Pent & & &
\end{tabular}

(Sumber: Data Primer Penelitian)

Hasil pengujian efektifitas antiketombe sampo ekstrak Sonneratia caseolaris L. dapat dilihat pada tabel 1, Formula sampo dengan konsentrasi F1 (15\%), F2 (30\%), F3 (60\%) sampo
Ketomed 2\% sebagai kontrol positif pada masing-masing perlakukan menunjukkan adanya zona hambat yang ditunjukkan dengan daerah bening yang terbentuk disekitar kertas cakram. Zona hambat yang 
terbentuk terus meningkat dengan adanya penambahan konsentrasi ekstrak Sonneratia caseolaris L. Di antara ketiga konsentrasi ekstrak Sonnerratia caseolaris L dalam formula sampo antiketombe, zona hambat terbesar terdapat pada sampo antiketombe yang mengandung ekstrak Sonnerratia caseolaris L dengan konsentrasi $60 \%$ (F3), sedangkan zona hambat terendah terdapat pada sampo antiketombe yang mengandung ekstrak Sonnerratia caseolaris L dengan konsentrasi $15 \%$ (F1). Semakin tinggi konsentrasi ekstrak Sonnerratia caseolaris L dalam formula sampo maka semakin tinggi pula kandungan zat aktif di dalamnya sehingga semakin besar aktivitas antijamur.

Tabel 2. Hasil Uji Normalitas

\begin{tabular}{lllllclc}
\hline & & \multicolumn{3}{c}{ Kolmogorov-Smirnov } & \multicolumn{3}{c}{ Shapiro-Wilk } \\
\cline { 3 - 8 } & Kode & Statistic & Df & Sig. & Statistic & df & Sig. \\
\hline \multirow{2}{*}{ rata } & formula1 & .328 & 3 &. & .871 & 3 & .298 \\
\cline { 2 - 8 } & formula2 & .175 & 3 &. & 1.000 & 3 & 1.000 \\
\cline { 2 - 8 } & formula3 & .385 & 3 &. & .750 & 3 & .278 \\
\hline
\end{tabular}

(Sumber: Data Primer Penelitian)

Tabel 3. Hasil Analisa One Way Anova

\begin{tabular}{lccccc}
\hline & $\begin{array}{c}\text { Sum of } \\
\text { Squares }\end{array}$ & df & Mean Square & F & Sig. \\
\hline $\begin{array}{l}\text { Between } \\
\text { Groups }\end{array}$ & 27.000 & 8 & 3.375 & 6.750 & .016 \\
\hline $\begin{array}{l}\text { Within } \\
\text { Groups }\end{array}$ & 3.000 & 6 & .500 & & \\
\hline Total & 30.000 & 14 & & & \\
\hline
\end{tabular}

(Sumber: Data Primer Penelitian)

Data hasil penelitian ini diuji normalitas menggunakan pengujian Shapiro-Wilk dengan nilai $>0.005$ didapatkan hasil normal. Pengujian dilanjutkan menggunakan One Way Anova dengan taraf kepercayaan 95\%. Hasilnya diketahui terdapat pengaruh yang bermakna dengan angka signifikasi 0.000 $<0.005$, sehingga dapat disimpulkan bahwa rata-rata kelima sampel uji tersebut berpengaruh secara signifikan.

Tabel 4. Kategori Penghambatan Antimikroba Berdasarkan Diameter Zona Hambat (Pan, dkk., 2009)

\begin{tabular}{cc}
\hline Diameter $(\mathrm{mm})$ & Respon hambatan pertumbuhan \\
\hline $0-3$ & Lemah \\
\hline $3-6$ & Sedang \\
\hline Lebih dari 6 & Kuat \\
\hline
\end{tabular}


Efektifitas sampo antiketombe ekstrak Sonnerratia caseolaris L dengan konsentrasi $0,15 \%$ (F1), 0,30\% (F2), dan $0,60 \%$ (F3) memiliki respon hambatan pertumbuhan jamur yang kuat dilihat dari kategori penghambatan antimikroba menurut tabel 4.

\section{KESIMPULAN}

Dari hasil yang diperoleh dapat disimpulkan bahwa buah pedada dapat dijadikan alternatif bahan utama bahan alam yang berfungsi sebagai antiketombe. Sifat fisik dari ketiga formula sampo ekstrak buah pedada (Sonnerratia caseolaris L) meliputi organoleptis, pengukuran $\mathrm{pH}$, pengukuran tinggi busa, cycling test, dan viskositas dihasilkan sifat fisik yang baik sesuai dengan standar uji sifat fisik sampo, namun hasil uji homogenitas menunjukan sampo formula III kurang homogen. Ketiga formula sampo efektif sebagai antiketombe terhadap jamur Candida albicans.

\section{DAFTAR PUSTAKA}

Ambarwati, Sujono, T. A., \& Sintowati, R. (2016). Uji Aktivitas Ekstrak Daun Pandan Wangi (Pandanus amaryllifolius Roxb.) sebagai Antibakteri. University Research Colloquium.

Atlas, R. (2004). Buku Pegangan Media Mikrobiologi. Jakarta: CRC Press.

Badan Standardisasi Standar Nasional Indonesia. (1992). SNI Sampoo (06-
2692-1992).

Mutiara, R., Djangi, M. J., \& Herawati, N. (2016). Isolasi dan Uji Aktivitas Antioksidan Senyawa Metabolit Sekunder Ekstrak Metanol Kulit Buah Mangrove Pidada ( Sonneratia caseolaris ) Isolation and Antioxidant Activity Test of Secondary Metabolites Compound Methanol Extract of Mangrove Pidada Rind' $s$ (. Jurnal Chemica, 17, 52-62.

Nurdiansyah. (2007). Efek Lama Maserasi Bubuk Kopra Terhadap Rendemen , Densitas , dan Bilangan Asam Biodiesel yang Dihasilkan dengan Metode Transesterifikasi In Situ. Jurnal Belian, 60(2), 218-224.

Pan, X., Chen, F., Wu, T., Tang, H., \& Zhao, Z. (2009). The acid, bile tolerance and antimicrobial property of Lactobacillus acidophilus NIT. Food Control. https://doi.org/10.1016/j.foodcont.200 8.08.019

Rieger, M. (2003). Harry's cosmeticology (8th ed New). New York: Chemical Publishin Company.

Sambodo, D. K., \& Arlesia, N. (2019).

Aktivitas antioksidan krim kombinasi ekstrak Eucheuma Cottonii Sumbawa dan ekstrak Citrus lemon L. impor dengan metode DPPH. Health Sciences and Pharmacy Journal. https://doi.org/10.32504/hspj.v3i1.95

Wilkinson, J. B., \& Moore, R. J. (1982). Harry's Cosmeticology (7th ed.). London: George Godwin. 